\title{
Nested case-control study of leukaemia, multiple myeloma, and kidney cancer in a cohort of petroleum workers exposed to gasoline
}

\author{
Otto Wong, Lisa Trent, Fran Harris
}

\begin{abstract}
Objectives-This nested case-control study was based on data in a cohort study of more than 18000 petroleum distribution workers exposed to gasoline, which contains about $2 \%-3 \%$ benzene. Risks of leukaemia, acute myeloid leukaemia, multiple myeloma, and kidney cancer were examined relative to exposure to gasoline. Methods-For each case, up to five individually matched controls were selected. Analyses based on the Mantel-Haenszel procedure as well as univariate and multivariate conditional logistic regression were performed for each disease category. Jobs with similar exposures were grouped into homogeneous categories for analysis. Several quantitative indices of exposure to gasoline were used in the analyses: duration of exposure, cumulative exposure, frequency of peak exposure, and time of first exposure.

Results-No increased risks for the four cancers were found for any job category. Analyses with logistic regression models based on duration of exposure, cumulative exposure, and frequency of peak exposure did not show any increased risk or exposure-effect relation. Time of first exposure to gasoline was also found to be
\end{abstract}

unrelated to the four diseases under investigation.

Conclusion-Exposure to gasoline or benzene at the concentrations experienced by this cohort of distribution workers is not a risk factor for leukaemia (all cell types), acute myeloid leukaemia, multiple myeloma, or kidney cancer.

(Occup Environ Med 1999;56:217-221)

Keywords: leukaemia; multiple myeloma; kidney cancer; gasoline; benzene

The present nested case-control study is based on data in a cohort mortality study of more than 18000 United States land based or marine distribution workers with exposure to gasoline, which contains about $2 \%-3 \%$ benzene. The overall results of the cohort study are summarised in table 1. For further details, readers are referred to the previous reports. ${ }^{12}$ In the original study design, it was proposed that case-control analyses for certain diseases of interest should be performed as well as the cohort analyses. The diseases initially chosen included total leukaemia, acute myeloid leukaemia (AML), multiple myeloma (because of benzene in gasoline), and kidney cancer (because of previous animal studies). In this
Applied Health

Sciences, San Mateo, California, USA

O Wong

L Trent

F Harris

Tulane University Medical Center, New Orleans, Louisiana, USA

O Wong

University of

California, San

Francisco, California, USA

F Harris

Correspondence to: Dr Otto Wong, Applied Health Sciences, 181 Second Avenue, Suite 628, PO Box 2078, San Mateo, California 94401, USA. Telephone 0016503477898.

Accepted 23 October 1998
Table 1 Observed and expected deaths, SMRs (95\% CIs) by cause among petroleum distribution workers exposed to gasoline in the United States

\begin{tabular}{lrrll}
\hline Causes of death & Observed & Expected & SMR & $95 \%$ CI \\
\hline All malignant neoplasms & 1081 & 1384.42 & $0.78^{\star \star}$ & 0.74 to 0.83 \\
Cancer of buccal cavity and pharynx & 20 & 42.06 & $0.48^{\star \star}$ & 0.29 to 0.73 \\
Cancer of digestive organs and peritoneum & 289 & 383.64 & $0.75^{\star \star}$ & 0.67 to 0.85 \\
Cancer of oesophagus & 29 & 33.86 & 0.86 & 0.57 to 1.23 \\
Cancer of stomach & 41 & 69.14 & $0.59^{\star \star}$ & 0.43 to 0.80 \\
Cancer of large intestine & 118 & 128.94 & 0.92 & 0.76 to 1.10 \\
Cancer of rectum & 23 & 42.38 & $0.54^{\star \star}$ & 0.34 to 0.81 \\
Cancer of biliary passages and liver & 20 & 24.60 & 0.81 & 0.50 to 1.26 \\
Cancer of pancreas & 57 & 76.52 & $0.74^{\star}$ & 0.56 to 0.96 \\
Cancer of respiratory system & 388 & 468.46 & $0.83^{\star \star}$ & 0.75 to 0.92 \\
Cancer of larynx & 15 & 20.35 & 0.74 & 0.41 to 1.22 \\
Cancer of bronchus, trachea, and lung & 373 & 444.18 & $0.84^{\star \star}$ & 0.76 to 0.93 \\
Cancer of bone & 5 & 5.97 & 0.84 & 0.27 to 1.96 \\
Cancer of skin & 23 & 21.99 & 1.05 & 0.66 to 1.57 \\
Cancer of prostate & 88 & 113.94 & $0.77^{\star}$ & 0.62 to 0.95 \\
Cancer of testes and other urinary organs & 2 & 6.06 & 0.33 & 0.04 to 1.19 \\
Cancer of bladder & 33 & 46.01 & 0.72 & 0.49 to 1.01 \\
Cancer of kidney & 24 & 32.69 & 0.73 & 0.47 to 1.09 \\
Cancer of brain and central nervous system & 26 & 34.26 & 0.76 & 0.50 to 1.11 \\
Cancer of thyroid and other endocrine glands & 2 & 2.49 & 0.80 & 0.10 to 2.90 \\
Cancer of lymphatic and haematopoietic tissue & 89 & 129.14 & $0.69^{\star \star}$ & 0.55 to 0.85 \\
Non-Hodgkin's lymphoma & 19 & 45.23 & $0.42^{\star \star}$ & 0.25 to 0.65 \\
Hodgkin's disease & 6 & 12.62 & 0.48 & 0.18 to 1.05 \\
Multiple myeloma & 17 & 21.52 & 0.79 & 0.46 to 1.24 \\
Leukaemia & 43 & 53.75 & 0.80 & 0.56 to 1.07 \\
Acute myeloid leukaemia & 18 & 15.38 & 1.17 & 0.69 to 1.85 \\
Benign neoplasms & 13 & 16.92 & 0.77 & 0.41 to 1.31 \\
Diseases of blood and blood forming organs & 10 & 15.43 & 0.65 & 0.31 to 1.19 \\
\hline × & & & &
\end{tabular}

${ }^{\star} \mathrm{p}<0.05 ;{ }^{\star \star} \mathrm{p}<0.01$ 
Table 2 Comparison of mean exposure indices between cases and controls

\begin{tabular}{lllll}
\hline & $\begin{array}{l}\text { Duration of } \\
\text { employment } \\
\text { (years) }\end{array}$ & $\begin{array}{l}\text { Duration of } \\
\text { exposure } \\
\text { (years) }\end{array}$ & $\begin{array}{l}\text { Cumulative } \\
\text { exposure } \\
\text { (ppm-years } \\
\text { THC) }\end{array}$ & $\begin{array}{l}\text { Peak exposure } \\
\text { (cumulative } \\
\text { frequency) }\end{array}$ \\
\hline $\begin{array}{l}\text { Leukaemia: } \\
\quad \text { Cases }\end{array}$ & 25.6 & 21.8 & 814 & 5832 \\
$\quad \begin{array}{l}\text { Controls } \\
\text { Acute myeloid leukaemia: }\end{array} \quad 27.9$ & 24.4 & 819 & 6074 \\
$\quad \begin{array}{l}\text { Cases } \\
\quad \text { Controls }\end{array}$ & 27.1 & 23.2 & 773 & 4895 \\
$\begin{array}{l}\text { Multiple myeloma: } \\
\quad \text { Cases }\end{array}$ & 29.5 & 23.4 & 837 & 5513 \\
$\quad$ Controls & 27.9 & 21.7 & 672 & 8178 \\
$\quad \begin{array}{l}\text { Kidney cancer: } \\
\quad \text { Cases }\end{array}$ & 27.9 & 25.3 & 800 & 6383 \\
$\quad$ Controls & 25.0 & 23.3 & 618 & 3456 \\
\hline
\end{tabular}

THC=total hydrocarbons. multiple myeloma (203), and 12 cases of kidney cancer (189).

For each case, up to five controls were selected from the remaining cohort-that is, among workers who were still alive at the end of the study and dead workers whose death certificates did not mention any of these four diseases. Controls were randomly selected with the following restrictions. To ensure an equal opportunity for potential exposure, the controls must be alive at the time of death of the corresponding case. Furthermore, they were individually matched to the corresponding case according to the following criteria: same company, date of birth (within 2 years), and same sex.

In the cohort study an extensive assessment of exposure to gasoline was performed. ${ }^{3}$ Exposure to gasoline was expressed in terms of parts per million (ppm) of total hydrocarbons (THCs), which represent a mixture of chemicals including aromatic and aliphatic hydrocarbons. One constituent of particular interest is benzene. According to data presented by the International Agency for Research on Cancer, ${ }^{4}$ there is a high correlation between air concentrations of THCs and benzene from gasoline, and under various conditions, the ratio between the two is about 100:1.6.

In the case-control analyses, several exposure variables were used: duration of employment, duration of exposure, job category, cumulative exposure (product of concentration and duration of exposure expressed as ppmyears in terms of THCs or benzene), cumulative frequency of peak exposure (defined as an episode of exposure in excess of $500 \mathrm{ppm}$ THCs for 15-90 minutes), and year of first exposure $(\leqslant 1948 v \geqslant 1949)$. The interest in year of first exposure stems from the finding that the recommended standard for benzene before 1947 was $100 \mathrm{ppm}$, which was reduced to $50 \mathrm{ppm}$ in 1947, and further reduced to 35 $\mathrm{ppm}$ in 1948. Thus, around 1947-9 the recommended benzene standard underwent considerable reduction.

The Mantel-Haenszel $\chi^{2}$ procedure (based on individually matched sets) was used to analyse job categories and year of first exposure. Univariate and multivariate conditional logistic regression procedures were used to analyse continuous variables such as years of exposure and cumulative exposure. In the analyses, exposures of controls were truncated at the time of death of the corresponding case.

Table 3 Relative risk (95\%CI) by cancer site and job category

\begin{tabular}{|c|c|c|c|c|}
\hline fob (ever) & Leukaemia & Acute myeloid leukaemia & Multiple myeloma & Kidney cancer \\
\hline Plantmen & $0.83(0.40$ to 1.72$)$ & $1.17(0.35$ to 3.91$)$ & $0.55(0.15$ to 2.10$)$ & $0.81(0.22$ to 2.95$)$ \\
\hline Warehousemen & $0.54(0.12$ to 2.40$)$ & 0 & $1.82(0.32$ to 10.4$)$ & $1.79(0.32$ to 9.95$)$ \\
\hline Labourers & $0.96(0.26$ to 3.51$)$ & $2.42(0.21$ to 27.4$)$ & 0 & $1.79(0.32$ to 9.95$)$ \\
\hline Mechanics & $0.83(0.30$ to 2.34$)$ & $0.91(0.17$ to 4.80$)$ & $0.45(0.05$ to 3.81$)$ & 0 \\
\hline Clerks or office & $0.53(0.18$ to 1.58$)$ & $0.33(0.04$ to 2.62$)$ & $0.29(0.04$ to 2.28$)$ & $0.87(0.24$ to 3.16$)$ \\
\hline Foremen or supervisors & $1.36(0.59$ to 3.18$)$ & $1.12(0.30$ to 4.18$)$ & $1.92(0.43$ to 8.59$)$ & $2.08(0.60$ to 7.26$)$ \\
\hline Maintenance & 0 & 0 & 0 & $1.27(0.13$ to 12.5$)$ \\
\hline Drivers & $0.77(0.35$ to 1.71$)$ & $0.42(0.13$ to 1.44$)$ & $0.91(0.21$ to 3.96$)$ & $1.15(0.32$ to 4.19$)$ \\
\hline Loaders & $0.79(0.09$ to 6.82$)$ & 0 & $1.00(0.11$ to 9.51$)$ & $5.73(0.88$ to 37.3$)$ \\
\hline Others & $0.89(0.41$ to 1.92$)$ & $0.62(0.17$ to 2.25$)$ & $0.80(0.21$ to 3.06$)$ & $1.87(0.54$ to 6.29$)$ \\
\hline
\end{tabular}


Table 4 Univariate conditional logistic regression analysis for kidney cancer, leukaemia, acute myeloid leukaemia, and multiple myeloma

\begin{tabular}{|c|c|c|c|c|c|c|}
\hline Model & Variables in the model & $\beta$ & $S E(\beta)$ & $\chi^{2}$ & $p$ Value & $R R^{*}$ \\
\hline \multicolumn{7}{|c|}{ Leukaemia: } \\
\hline 1 & Duration of employment (y) & -0.026112 & 0.020450 & 1.631 & 0.202 & 0.97 \\
\hline 2 & Duration of exposure $(y)$ & -0.013375 & 0.018340 & 0.532 & 0.466 & 0.99 \\
\hline 3 & Cumulative exposure (ppm-y THC) & -0.000003 & 0.000318 & 0.000 & 0.993 & 1.00 \\
\hline 4 & Frequency of peak exposure & -0.000006 & 0.000034 & 0.028 & 0.868 & 1.00 \\
\hline 5 & Year of first exposure $\dagger$ & -0.549856 & 0.553380 & 0.987 & 0.320 & 0.58 \\
\hline \multicolumn{7}{|c|}{ Acute myeloid leukaemia: } \\
\hline 1 & Duration of employment (y) & -0.031112 & 0.034410 & 0.818 & 0.366 & 0.97 \\
\hline 2 & Duration of exposure (y) & 0.002738 & 0.029530 & 0.009 & 0.926 & 1.00 \\
\hline 3 & Cumulative exposure (ppm-y THC) & -0.000032 & 0.000527 & 0.004 & 0.951 & 1.00 \\
\hline 4 & Frequency of peak exposure & -0.000007 & 0.000055 & 0.015 & 0.901 & 1.00 \\
\hline 5 & Year of first exposure & -0.315322 & 0.948050 & 0.111 & 0.739 & 0.73 \\
\hline \multicolumn{7}{|c|}{ Multiple myeloma: } \\
\hline 1 & Duration of employment (y) & 0.000244 & 0.038260 & 0.000 & 0.995 & 1.00 \\
\hline 2 & Duration of exposure (y) & -0.038776 & 0.034580 & 1.257 & 0.262 & 0.96 \\
\hline 3 & Cumulative exposure (ppm-y THC) & -0.000536 & 0.000732 & 0.536 & 0.464 & 1.00 \\
\hline 4 & Frequency of peak exposure & 0.000046 & 0.000052 & 0.790 & 0.374 & 1.00 \\
\hline 5 & Year of first exposure $\dagger$ & 0.644938 & 1.125110 & 0.329 & 0.567 & 1.91 \\
\hline \multicolumn{7}{|c|}{ Kidney cancer: } \\
\hline 1 & Duration of employment (y) & -0.027584 & 0.039670 & 0.484 & 0.487 & 0.97 \\
\hline 2 & Duration of exposure (y) & 0.001030 & 0.035180 & 0.001 & 0.977 & 1.00 \\
\hline 3 & Cumulative exposure (ppm-y THC) & -0.000477 & 0.005243 & 0.827 & 0.363 & 1.00 \\
\hline 4 & Frequency of peak exposure & -0.000011 & 0.000066 & 0.028 & 0.867 & 1.00 \\
\hline 5 & Year of first exposuret & -1.115231 & 0.815680 & 1.869 & 0.172 & 0.33 \\
\hline
\end{tabular}

$\star R R$ corresponds to an increment of 1 unit of the independent variable.

$\dagger \leqslant 1948 v \geqslant 1949$.

THC=total hydrocarbons.

\section{Results}

For most cases, we were able to select five matched controls. For one case of AML, no eligible control could be found. For the remaining cases of AML, five controls were selected for each. For leukaemia (all cell types), as well as the case of AML with no controls, one case had only three controls. Five controls were selected for each of the remaining cases of leukaemia, multiple myeloma, and kidney cancer.

Four key exposure variables (duration of employment, duration of exposure, cumulative exposure, and frequency of peak exposure) were compared between the cases and controls for the four disease categories (table 2). The cases had similar or slightly lower means of these four exposure variables than had the controls.

Table 3 shows the Mantel-Haenszel relative risks (RRs) for the four disease categories by ever or never job category. No significantly increased risk of leukaemia was detected for any job category. For AML, except for the category labourers, which consisted of only one case, no job category showed any excess. For multiple myeloma, no significant excess was found. However, for those who had ever been foremen or supervisors, the RR was 1.92 (based on three cases, $\mathrm{p}>0.05 ; 95 \%$ CI 0.43 to 8.59). For kidney cancer, no significant excess was found for any job category. However, non-

Table 5 Multivariate conditional logistic regression analysis for leukaemia, acute myeloid leukaemia, multiple myeloma, and kidney cancer

\begin{tabular}{|c|c|c|c|c|c|c|}
\hline Model & Variables in the model & $\beta$ & $\operatorname{SE}(\beta)$ & $\chi^{2}$ & $p$ Value & $R R^{\star}$ \\
\hline \multicolumn{7}{|c|}{ Leukaemia: } \\
\hline \multirow[t]{2}{*}{1} & Duration of exposure (y) & -0.015262 & 0.019680 & 0.601 & 0.438 & 0.98 \\
\hline & Cumulative exposure (ppm-y THC) & 0.000089 & 0.000332 & 0.071 & 0.789 & 1.00 \\
\hline \multirow[t]{2}{*}{2} & Duration of exposure (y) & -0.016621 & 0.022130 & 0.564 & 0.453 & 0.98 \\
\hline & Frequency of peak exposure & 0.000011 & 0.000041 & 0.071 & 0.790 & 1.00 \\
\hline \multirow[t]{2}{*}{3} & Cumulative exposure (ppm-y THC) & 0.000031 & 0.000362 & 0.007 & 0.933 & 1.00 \\
\hline & Frequency of peak exposure & -0.000007 & 0.000039 & 0.035 & 0.852 & 1.00 \\
\hline \multicolumn{7}{|c|}{ Acute myeloid leukaemia: } \\
\hline \multirow[t]{2}{*}{1} & Duration of exposure (y) & 0.003672 & 0.031160 & 0.014 & 0.906 & 1.00 \\
\hline & Cumulative exposure (ppm-y THC) & -0.000053 & 0.000562 & 0.009 & 0.924 & 1.00 \\
\hline \multirow[t]{2}{*}{2} & Duration of exposure (y) & 0.006950 & 0.035440 & 0.038 & 0.845 & 1.01 \\
\hline & Frequency of peak exposure & -0.000014 & 0.000066 & 0.046 & 0.831 & 1.00 \\
\hline \multirow[t]{2}{*}{3} & Cumulative exposure (ppm-y THC) & 0.000000 & 0.000602 & 0.000 & 1.000 & 1.00 \\
\hline & Frequency of peak exposure & -0.000007 & 0.000063 & 0.012 & 0.914 & 1.00 \\
\hline \multicolumn{7}{|c|}{ Multiple myeloma: } \\
\hline \multirow[t]{2}{*}{1} & Duration of exposure (y) & -0.033747 & 0.038630 & 0.763 & 0.382 & 0.97 \\
\hline & Cumulative exposure (ppm-years THC) & -0.000218 & 0.000755 & 0.083 & 0.773 & 1.00 \\
\hline \multirow[t]{2}{*}{2} & Duration of exposure (y) & -0.098083 & 0.052870 & 3.441 & 0.064 & 0.91 \\
\hline & Frequency of peak exposure & 0.000153 & 0.000089 & 2.980 & 0.084 & 1.00 \\
\hline \multirow[t]{2}{*}{3} & Cumulative exposure (ppm-y THC) & -0.001226 & 0.001040 & 1.381 & 0.240 & 1.00 \\
\hline & Frequency of peak exposure & 0.000088 & 0.000065 & 1.850 & 0.174 & 1.00 \\
\hline \multicolumn{7}{|c|}{ Kidney cancer: } \\
\hline \multirow[t]{2}{*}{1} & Duration of exposure (y) & 0.007465 & 0.035870 & 0.043 & 0.835 & 1.01 \\
\hline & Cumulative exposure (ppm-y THC) & -0.000502 & 0.000550 & 0.831 & 0.362 & 1.00 \\
\hline \multirow[t]{2}{*}{2} & Duration of exposure (y) & 0.003560 & 0.037650 & 0.009 & 0.925 & 1.00 \\
\hline & Frequency of peak exposure & -0.000013 & 0.000070 & 0.036 & 0.850 & 1.00 \\
\hline \multirow[t]{2}{*}{3} & Cumulative exposure (ppm-y THC) & -0.000510 & 0.000566 & 0.810 & 0.368 & 1.00 \\
\hline & Frequency of peak exposure & 0.000012 & 0.000069 & 0.033 & 0.857 & 1.00 \\
\hline
\end{tabular}

$\star \mathrm{RR}$ corresponds to an increment of 1 unit of the independent variable. 
significant increases were reported for loaders, foremen or supervisors, warehousemen, and labourers. Analyses by job category with a minimum duration of 5 or 10 years showed similar results, and will not be presented in this report.

As discussed earlier, based on a consideration of the reduction in recommended benzene standards in 1947 and 1948, the risk of developing the four diseases among those first exposed before 1949 was compared with that among those exposed thereafter. The RRs (95\% CIs) were: 0.73 (0.32 to 1.66$)$ for leukaemia, 0.92 (0.22 to 3.89) for AML, 1.39 (0.27 to 7.33 ) for multiple myeloma, and 0.52 (0.16 to 1.73 ) for kidney cancer.

Results based on univariate conditional logistic regression are shown by disease category in table 4 . In these univariate analyses, only one exposure variable was in the logistic model. Based on these univariate models, no association was found between any of the exposure variables and any of the four diseases.

Results of the multivariate conditional logistic regression analyses are presented in table 5 . In these models, various combinations of exposure variables were used-such as, duration of exposure and frequency of peak exposure, cumulative exposure, and frequency of peak exposure, etc. No significant association was detected between the exposure variables and any of the diseases in the multivariate logistic regression models.

\section{Discussion}

In the case-control study, job categories and exposure estimates were further refined, resulting in 10 more specific job categories. For example, the broad job category terminal operators, which was used in the cohort study previously, was broken down into additional categories, including plantmen, warehousemen, labourers, mechanics, foremen or supervisors, and maintenance or yard workers. Exposures within these subcategories were more homogeneous than those in the previous overall category terminal operators.

Analysis by newly developed job categories did not find any significantly increased risk for any of the four diseases. However, nonsignificant excesses were detected among foremen or supervisors for leukaemia, multiple myeloma, and kidney cancer. From the exposure point of view, the category foremen or supervisors is considered to be a group with low exposure. On the other hand, among other job categories examined, mechanics and maintenance or yard workers were considered to have higher exposure than the others. Neither of these two groups showed an excess in leukaemia (all cell types), AML, multiple myeloma, or kidney cancer. Thus, the excesses found among foremen or supervisors could not be explained in terms of their level of exposure.

As well as job categories, other exposure variables were used in the case-control analyses. Included in the logistic regression analyses were several quantitative exposure indices. Analyses based on univariate logistic regression did not indicate any relation between the diseases of interest and quantitative gasoline or benzene exposure indices. As these exposure indices correlated with one another, multiple logistic regression models were also used. For example, cumulative exposure was highly dependent on duration of exposure. In one of the models, both cumulative exposure and duration of exposure were analysed simultaneously. Again, no associations between any of the four disease categories and any of the exposure indices were found. These case-control analyses based on logistic regression confirmed the findings based on subcohort analyses of standardised mortality ratio (SMR) and proportional hazards models reported in the original cohort study. ${ }^{12}$

A similar conclusion was reached in a nested case-control study of lymphohaematopoietic cancers in Canadian distribution workers. ${ }^{5}$ Exposures were assessed in terms of cumulative exposure and intensity of exposure. No relations between exposure to total hydrocarbons (or benzene) and any of the lymphatic and haematopoietic cancers (leukaemia, multiple myeloma, non-Hodgkin's lymphoma) were found. For example, for exposure to benzene, the odds ratios for multiple myeloma were $1.00,0.44,1.44$, and 0 for cumulative exposure categories $0.0-0.90,>0.90-9.9,>9.9-9.99$, and $>9.99$ ppm-years, respectively.

Exposures to benzene among distribution workers were relatively low. For example, one of the most highly exposed jobs in distribution workers was driver for small terminals from 1950 to 1965: 8 hour time weighted average (8 h TWA) of $210 \mathrm{ppm}$ THCs, which is about 3-4 ppm benzene. By contrast, in populations of workers reported to have an increased risk of AML in previous studies, exposure to benzene was much higher. For example, it was reported that shoemakers in Turkey, who used solvents containing up to $88 \%$ benzene, were exposed to concentrations of benzene in air as high as $650 \mathrm{ppm},{ }^{6}$ and Pliofilm workers in Ohio to peaks as high as $750 \mathrm{ppm}$ and $8 \mathrm{~h}$ TWAs as high as $260 \mathrm{ppm} .{ }^{7}$ Recently, based on the Pliofilm study and with exposure values which were most likely underestimated, Wong reported that no excess AML was found among workers with cumulative exposure to benzene $<200$ ppm-years. ${ }^{8}$ Had more realistic exposure estimates been used, the AML threshold would most likely be in the range of 370-530 ppm-years. Among distribution workers in our study, on the other hand, cumulative exposure was up to 8000 ppm-years of THCs or 128 ppm-years of benzene. Thus, exposure to benzene in this cohort was not sufficient to increase the risk of AML. This statement is supported by the lack of an exposure-effect relation based on analyses in the cohort study and case-control study.

For multiple myeloma, no association with exposure to gasoline was found in this case-control study. Suggestions for an association between exposure to benzene and multiple myeloma came primarily from the study of Pliofilm workers in Ohio. ${ }^{9}$ Although a significant increase of multiple myeloma was found in that study in a previous update, the increase 
was only marginally significant. More importantly, three of the four cases of multiple myeloma in the Pliofilm study were short term workers, including one who worked at the factory for 4 days, and no exposure-response relation was found. Based on the most recently updated data, the increase in multiple myeloma was no longer significant. ${ }^{8}$ The conclusion of no association between exposure to gasoline or benzene and multiple myeloma is further supported by several population based casecontrol studies and a recent comprehensive review of studies of petroleum workers. ${ }^{10-15}$

For kidney cancer, analyses in the nested case-control study indicate that the risk of developing kidney cancer is not related to exposure to gasoline or benzene. As indicated in table 2, the cases of kidney cancer and their controls had similar exposures. Based on the more refined job classification in the casecontrol study, no job category was found to be significantly related to risk of kidney cancer. The finding of a fivefold risk ratio for loaders was based on only two cases of kidney cancer, and the risk ratio was not significant. More importantly, based on logistic regression analyses, none of the exposure indices were found to be associated with an increased risk of kidney cancer. Thus, little interpretation can be attached to the isolated finding of a nonsignificant increased risk ratio in loaders. Taking all the results into consideration, the analyses in the nested case-control study indicate that exposure to gasoline is not related to an increased risk of kidney cancer. A similar case-control study of kidney cancer in petroleum workers concluded that no increased risk of kidney cancer resulted from exposure to gasoline. ${ }^{16}$

Exposure information in the case-control analyses was limited to employment in the petroleum industry. No information on lifestyle, previous medical histories, or information on employment outside the petroleum industry was available to control potential confounding effects. Many substances as well as personal factors have been reported to be associated with an increased risk of the diseases under investigation. Unfortunately, it was beyond the scope of this case-control study to collect information on these confounding factors.

\section{Conclusion}

In this nested case-control study, more specific and more homogeneous job classifications and exposure estimates than those used in the original cohort study were developed and used in the analysis. Based on the results of this case-control study, we conclude that exposures to gasoline or benzene at the concentrations experienced by this cohort of distribution workers are not significant risk factors for leukaemia (all cell types), AML, multiple myeloma, or kidney cancer.

We thank Professor Thomas J Smith (Harvard University) for the assessment of exposure ; Professor Philip E Enterline (University of Pittsburgh), Professor Melvin W First (Harvard University) and Professor David H Wegman (University of Massachusetts) for review and suggestions throughout the project; the American Petroleum Institute Epidemiology Task Force for American Petroleum Institute Epidemiology Task Force for
valuable support and assistance; the four participating companies (Chevron, Exxon, Mobil, and Shell) for data; Mr Robert Bilgrad and the National Death Index of the National Center for Health Statistics for information on vital status; state health departments for providing death certificates; and the American Petroleum Institute for sponsoring the project.

1 Wong $\mathrm{O}$, Harris F. A mortality study of marketing and marine distribution workers with potential exposure to gasoline in the petroleum industry. Washington, DC: American Petroleum Institute, 1992. (Publication No 4555.)

2 Wong O, Harris F, Smith TJ. Health effects of gasoline exposure. II. Mortality patterns of distribution workers in the United States. Environ Health Perspect 1993;101(suppl 6):63-76

3 Smith TJ, Hammond SK, Hallock M, et al. Health effects of gasoline exposure. I. Exposure assessment for US distribution workers. Environ Health Perspect 1993;101(suppl 6):13-21.

4 International Agency for Research on Cancer. IARC Monographs on the evaluation of carcinogenic risks to humans. Vol 45. Lyon: IARC, 1989.

5 Schnatter AR, Armstrong TW, Nicolich MJ, et al. Lymphohaematopoietic malignancies and quantitative estimates of exposure to benzene in Canadian petroleum distribution workers. Occup Environ Med 1996;53:773-81.

6 Aksoy M, Erdem S, DinCol G. Leukemia in shoe-workers exposed chronically to benzene. Blood 1974;44:837-41.

7 Paustenbach DJ, Price PS, Ollison W, et al. Reevaluation of benzene exposure for the Pliofilm (rubberworkers) cohort (1936-76). F Toxicol Environ Health 1992;36:177-231.

8 Wong O. Risk of acute myeloid leukemia and multiple myeloma in workers exposed to benzene. Occup Environ Med 1995;52:380-4

9 Rinsky RA, Smith AB, Hornung R, et al. Benzene and leukemia, an epidemiologic risk assessment. $N$ Engl f Med 1987;316:1044-50.

10 Linet MS, Harlow SD, McLaughlin JK. A case-control study of multiple myeloma in whites: chronic antigenic stimulation, occupation, and drug use. Cancer Res 1987;47: 2978-81.

11 Morris PD, Koepsell TD, Daling JR, et al. Toxic substance exposure and multiple myeloma: a case-control study. $\mathcal{F}$ Natl Cancer Inst 1986;76:987-94.

12 Cuzick J, Stavola BD. Multiple myeloma: a case-control study. Br F Ind Med 1988;57:516-20.

13 Eriksson M, Karlsson M. Occupational and other environmental factors and multiple myeloma: a population based case-control study. Br F Ind Med 1992;49:95-103.

14 Flodin U, Fredriksson M, Persson B. Multiple myeloma and engine exhausts, fresh wood, and creosote: a case-referent study. Am f Ind Med 1987;12:519-29.

15 Wong O, Raabe GK. Multiple myeloma and benzene exposure in a multinational cohort of more than 250000 petroleum workers. Reg Toxicol Pharmacol 1997; 26:188-99.

16 Wen CP. Epidemiological studies of kidney cancer with particular reference to gasoline exposure. In: Proceedings of the workshop of the kidney effects of hydrocarbons, Boston, fuly 1983. Washington, DC: American Petroleum Institute, 1983. 